\title{
Muscle Capillary Basement Membrane Width in Patients with Vacor-induced Diabetes Mellitus
}

Kenneth R. Feingold, Tai Hee Lee, Min Young Chung, and Marvin D. Siperstein

Metabolism Section, Medical Service, Veterans Administration Medical Center, and Department of Medicine, University of California, San Francisco, California 94121; and Department of Endocrinology and Metabolism, Chonnam University Medical School, Kwang Ju, Korea

\begin{abstract}
Muscle capillary basement membrane width is a sensitive marker for the presence of diabetic microangiopathy. Studies have indicated that genetic factors and alterations in glucose metabolism influence muscle capillary basement membrane width. To define the role of these factors we have measured muscle capillary basement membrane thickness in controls, insulin dependent diabetics, and individuals with diabetes secondary to the ingestion of Vacor, a rat poison, which results in hyperglycemia. Hemoglobin $\mathbf{A}_{1}$ concentrations were increased in both diabetic groups, but hemoglobin $A_{1}$ levels and the duration of diabetes were similar in the two diabetic groups. The muscle capillary basement membrane width was increased to a similar extent in the insulindependent diabetics (control, 1,781 \pm 46 vs. IDD, $2,287 \pm 144 \AA$, $P<0.001)$ and in the Vacor diabetic group $(2,320 \pm 149 \AA, P$ $<0.001$ ). In the insulin-dependent diabetic group, $63 \%$ of the patients had a muscle capillary basement membrane width greater than two standard deviations above the mean of the controls, while in the Vacor diabetic group this figure was $56 \%$. Despite the relatively short duration of diabetes $(6.2 \pm 0.3 \mathrm{yr})$, $44 \%$ of the Vacor diabetic patients had retinopathy and $28 \%$ had proteinuria. The present study provides strong evidence that even in the absence of genetic diabetes mellitus, hyperglycemia or some other abnormality related to insulin lack can cause microvascular changes.
\end{abstract}

\section{Introduction}

Muscle capillary basement membrane thickening is a sensitive marker for the presence of diabetic microangiopathy (1-4). The mechanism by which diabetes results in microangiopathy and muscle capillary basement membrane thickening is unknown, but a number of studies have indicated that alterations in glucose metabolism or other abnormalities that occur in association with poorly controlled diabetes lead to an increase in muscle capillary basement membrane width. Raskin et al. longitudinally quantitated muscle capillary basement membrane width in insulindependent diabetics (IDD) ${ }^{1}$ who were either tightly controlled by continuous subcutaneous insulin infusion or treated conven-

Address reprint requests to Dr. Feingold, Veterans Administration Medical Center.

Received for publication 10 February 1986.

1. Abbreviations used in this paper: $\mathrm{HbA}_{1}$, glycosylated hemoglobin; IDD, insulin-dependent diabetics.

J. Clin. Invest.

(C) The American Society for Clinical Investigation, Inc.

0021-9738/86/07/0102/06 \$1.00

Volume 78, July 1986, 102-107 tionally (5). These investigators observed that in the tightly controlled diabetics, muscle capillary basement membrane width decreased, whereas in the conventionally treated group, muscle capillary basement membrane width at two years was not significantly different from baseline (5). In addition, muscle capillary basement membrane width, after two years of tight control, was similar in the tightly controlled diabetic group and in nondiabetic controls (5). Camerini-Davalos et al. examined the effect of glipizide or placebo treatment on muscle capillary basement membrane width in patients with impaired glucose tolerance (6). In the glipizide-treated group glucose tolerance improved, and muscle capillary basement membrane decreased to a width that was no different than that observed in controls (6). In contrast, in the placebo-treated group there was no change in glucose tolerance and muscle capillary basement width increased (6). In addition to these controlled studies, Peterson et al. reported that meticulous diabetic control for 8-10 mo decreased muscle capillary basement membrane width in six of seven IDD (7). Finally, Soskeno et al. serially biopsied a group of IDD and found that at least in the postpubertal individuals, the change in muscle capillary basement membrane width correlated positively with indicies of glycemic control (8). Taken together, these studies indicate that the degree of metabolic control in diabetic individuals affects muscle capillary basement membrane thickness.

It should be recognized, however, that several lines of evidence have suggested that genetic factors may also play an important role in the development of muscle capillary basement membrane thickening in humans with diabetes mellitus. In 1968, Siperstein, Unger, and Madison published data demonstrating that thickening of the muscle capillary basement membrane occurs before the onset of clinically demonstrable abnormalities in glucose metabolism (1). Specifically it was noted that in a group of nondiabetic offspring of two diabetic parents, muscle capillary basement membrane was significantly thickened in comparison to controls, a difference that persisted after age matching (1). Approximately $50 \%$ of the nondiabetic offspring of two diabetic parents had muscle capillary basement membrane thickening greater than two standard deviations above the mean of controls (1). Not unexpectedly, the finding of an abnormality in muscle capillary basement membrane width in nondiabetics genetically predisposed to the development of diabetes caused a great deal of controversy. Williamson (9), using a different technique to measure muscle capillary basement membrane width, was unable to duplicate these observations. However, Camerini-Davalos et al. (10) quantitated muscle capillary basement membrane width in the offspring of two diabetic parents using methods similar to those of Siperstein et al. (1), and also found "that in certain subjects highly predisposed to diabetes on a genetic basis, changes may occur in the microvessels before detectable hyperglycemia" (10). Additionally, a National Institutes of Health cooperative study demonstrated that in Pima 
Indians muscle capillary basement membrane width was increased in the nondiabetic offspring of two parents (Aronoff, S. L., P. H. Bennett, N. B. Rushforth, M. D. Siperstein, and J. R. Williamson, manuscript submitted for publication). Thus, data from several independent studies indicate that many of the offspring of two diabetic parents have thickening of muscle capillary basement membranes without any detectable abnormalities in glucose metabolism.

Another approach to determine the role of genetics in causing muscle capillary basement membrane thickening has been to study monozygote twins who were discordant for diabetes. Ganda et al. reported that 10 of 12 IDD twins had significantly thickened quadriceps muscle capillary basement membranes in comparison with controls, but more significantly, 9 of 12 of the nondiabetic twins also had significant thickening of their quadriceps muscle capillary basement membranes as compared with controls (11). In fact, 9 of 12 twin patients were concordant for either the presence or absence of quadriceps muscle capillary basement membrane thickening (11). Barnett also compared quadriceps muscle capillary basement membrane in monozygote twins who were discordant for diabetes, and they observed that zero of seven nondiabetic twins had a significant increase in muscle capillary basement width (12). However, in this study only three of the seven overt diabetic twins had thickened muscle capillary basement membrane width and only two of these seven diabetic twins had a significant increase in muscle capillary basement membrane width in comparison with their nondiabetic twins (12). If one combines the data from these two studies, in which the basement membrane width was measured in the same laboratory, one finds an impressive degree of concordance between diabetic and nondiabetic identical twins for the presence or absence of quadriceps muscle capillary basement membrane thickening. Steffes et al. have also observed recently that values of mean capillary basement membrane width were similar in diabetic and nondiabetic identical twins (13). Interestingly, these investigators did observe an increase in glomerular basement membrane width, tubular basement membrane width, and mesangial volume in the diabetic twins as compared with their nondiabetic identical siblings (13).

Approaching this issue in a different way, Marks et al. measured the mean capillary basement membrane width in first degree relatives of children with insulin-dependent diabetes (14). They found that muscle capillary membrane width was increased in the nondiabetic parents of diabetic children as compared with controls (14). Moreover, the width of the muscle capillary basement membrane in the parents of diabetic children was related to HLA phenotype, with parents with HLA DR-4 having a muscle capillary basement membrane width greater than either the controls or parents without the DR-4 gene (14). Taken together, these studies suggest that in addition to abnormalities in metabolic status, genetic factors also play a role in the development of diabetic microvascular disease.

To define better the relationship of genetic and environmental factors in diabetic microvascular disease one could determine the effect of secondary hyperglycemia on microangiopathy. Studies of the influence of conditions such as pancreatic disorders on microangiopathy and muscle capillary basement width have given contradictory results perhaps because a genetic predisposition to hyperglycemia in these conditions may contribute to the vascular lesions $(1,15-20)$. For this reason we have carried out a study of muscle capillary basement membrane width in subjects who developed hyperglycemia secondary to the ingestion of Vacor. Vacor is a rat poison which, when ingested, results in the destruction of the beta cells in the pancreas, in a fashion analogous to that of streptozotocin, and thereby induces diabetes (21-25). In addition, Vacor also has extra pancreatic effects that contribute to the hyperglycemia (26). Studies of muscle capillary basement membrane width in Vacor-induced hyperglycemia should therefore indicate whether hyperglycemia per se causes microangiopathy.

\section{Methods}

Controls, IDD, and Vacor-induced diabetics were recruited from the Endocrine-Metabolism Clinic of the Chonnam University Medical School. The individuals in all three groups were questioned regarding the presence or absence of any family members or relatives with diabetes mellitus and were excluded from the study if there was any history of diabetes mellitus in the family. In all cases, Vacor ingestion occurred during an unsuccessful suicide attempt. The procedure of Siperstein et al. was used to quantitate capillary basement membrane width (1). In brief, a 10-20-mg biopsy of muscle was obtained from the lateral aspect of the quadriceps muscle at the point midway between the knee and the hip of each subject with a modified Franklin-Silverman needle. The biopsies were immediately fixed in Palade's buffered osmium tetroxide fixative. After $60 \mathrm{~min}$ of fixation the specimens were placed in $3.7 \%$ formaldehyde for $30 \mathrm{~min}$ and then dehydrated in ethanol. The samples were then coded and mailed to the Veterans Administration Medical Center for further analysis. The tissue was next embedded in Maraglas and ultra-thin sections were cut with a diamond knife. Electron micrographs were obtained with a Zeiss $10 \mathrm{~A}$ electron-microscope and in each individual the basement membrane thickness was measured as previously described. All measurements were made without knowledge of the group to which the patient belonged.

Serum creatinine levels were determined using reagents purchased from Gilford Diagnostics, Oberlin, $\mathrm{OH}$, and glycosylated hemoglobin $\left(\mathrm{HbA}_{1}\right)$ levels were determined using reagents provided by Sigma Chemical Co., St. Louis, MO. The presence of proteinuria was measured by routine urinalysis and the presence of retinopathy was determined by routine funduscopic examination.

The significance of difference between groups was assessed with a two-tailed $t$ test and chi-square analysis.

\section{Results}

Tables I-IV present the clinical characteristics of the patients studied. The age and sex distribution is similar in the three groups. The duration of diabetes and serum creatinine levels in the insulin-dependent and Vacor-induced diabetic groups are also similar. As expected, the $\mathrm{HbA}_{1}$ concentrations are increased in both diabetic groups in comparison to controls, but there are no differences between the IDD patients and the Vacor-induced diabetic patients. All the patients in the Vacor-induced diabetic group were receiving insulin therapy. In none of the three groups were there any individuals with a family history of diabetes mellitus. Note that despite the relatively short duration of diabetes, $44 \%$ of the Vacor-induced diabetic patients had evidence of retinopathy on routine funduscopic examination and $28 \%$ had proteinuria on routine urinalysis.

As shown in Tables I, II, III, and V, the muscle capillary basement membrane width is significantly increased in the IDD group in comparison with the control group (controls, 1,781 \pm 46 $\AA$ vs. IDD, $2,287 \pm 144 \AA, P<0.001)$. More importantly, the muscle capillary basement membrane width is also increased in the Vacor-induced diabetic group (control, $1,781 \pm 46 \AA$ vs. Vacor-induced diabetics, $2,320 \pm 149 \AA, P<0.001$ ). Note that the mean muscle capillary basement membrane width is similar in the Vacor and IDD groups. As shown in Table V, in the IDD 
Table I. Controls

\begin{tabular}{|c|c|c|c|c|}
\hline Patient code & Age & $\operatorname{Sex}(M / F)$ & $\mathrm{HbA}_{1}$ & $\begin{array}{l}\text { MCBM width } \\
\text { (mean } \AA)\end{array}$ \\
\hline & $y r$ & & $\%$ & \\
\hline 17 & 28 & $\mathbf{M}$ & 5.3 & 1,838 \\
\hline 18 & 27 & F & 6.1 & 1,831 \\
\hline 19 & 24 & $F$ & 5.9 & 1,802 \\
\hline 20 & 28 & $F$ & 6.2 & 1,847 \\
\hline 21 & 18 & $\mathbf{M}$ & 5.0 & 1,645 \\
\hline 22 & 24 & $F$ & 6.3 & 1,368 \\
\hline 23 & 32 & $\mathrm{~F}$ & 6.7 & 1,786 \\
\hline 24 & 37 & $\mathbf{F}$ & 6.2 & 1,942 \\
\hline 25 & 54 & $\mathbf{F}$ & 6.9 & 1,931 \\
\hline 26 & 28 & $\mathbf{F}$ & 7.2 & 1,675 \\
\hline 27 & 26 & $\mathbf{F}$ & 6.4 & 1,740 \\
\hline 28 & 27 & $\mathbf{F}$ & 5.2 & 1,596 \\
\hline 29 & 24 & $\mathbf{F}$ & 6.2 & 1,629 \\
\hline 30 & 22 & $\mathbf{F}$ & 5.6 & 1,837 \\
\hline 31 & 24 & $\mathbf{F}$ & 6.5 & 2,222 \\
\hline 50 & 27 & $\mathbf{F}$ & - & 1,723 \\
\hline 51 & 26 & $F$ & - & 1,485 \\
\hline 63 & 29 & $\mathbf{M}$ & 7.1 & 2,049 \\
\hline 64 & 23 & $\mathbf{M}$ & 6.2 & 1,576 \\
\hline 65 & 26 & $\mathbf{F}$ & 6.5 & 2,091 \\
\hline Mean \pm SEM & $27.7 \pm 1.6$ & $4 \mathrm{M} / 16 \mathrm{~F}$ & $6.19 \pm 0.14$ & $1,781 \pm 46.4$ \\
\hline
\end{tabular}

MCBM, muscle capillary basement membrane.

group, $63 \%$ of the patients had muscle capillary basement membrane width greater than two standard deviations above the mean of the controls, while in the Vacor-induced diabetic group this figure was $56 \%$. In both the insulin-dependent and Vacor-in- duced diabetic groups there was no significant difference in age, duration of diabetes, or $\mathrm{HbA}_{1}$ levels in those individuals whose muscle capillary basement membrane widths were less than or greater than two standard deviations above the mean of controls (IDD: $>2$ SD $(n=9)$, age $27.6 \pm 2.9 \mathrm{yr}$, duration of diabetes $5.4 \pm 2.3 \mathrm{yr}, \mathrm{HbA}_{1} 12.1 \pm 0.7 \%$ vs. $<2 \mathrm{SD}(n=7)$, age $25.8 \pm 2.0$ $\mathrm{yr}$, duration of diabetes $3.5 \pm 1.1 \mathrm{yr}, \mathrm{HbA}_{1} 11.6 \pm 0.9 \%$; Vacorinduced diabetes: $>2 \mathrm{SD}(n=10)$, age $27.1 \pm 1.4 \mathrm{yr}$, duration of diabetes $6.1 \pm 4 \mathrm{yr}, \mathrm{HbA}_{1} 12.1 \pm 2 \%$ vs. $<2 \mathrm{SD}(n=8)$, age $29.5 \pm 3.9 \mathrm{yr}$, duration of diabetes $6.4 \pm 6 \mathrm{yr}, \mathrm{HbA}_{1} 12.0 \pm 0.3 \%$ ). These observations indicate that thickening of muscle capillary basement membrane occurs in Vacor-induced diabetes to a similar degree as observed in matched patients with insulin-dependent diabetes.

There is no correlation between muscle capillary basement membrane width and $\mathrm{HbA}_{1}$ levels in either the IDD, the Vacorinduced diabetics, or both diabetic groups taken as a whole. In neither the insulin-dependent nor Vacor-induced diabetic is basement membrane width correlated with retinopathy or proteinuria, and an increase in muscle capillary basement membrane width in those patients with evidence of clinical microangiopathy is not observed (IDD group: with microvascular disease $(n=5)$, $2,090 \pm 254$ vs. without microvascular disease $(n=11)$, $2,376 \pm 176 \mathrm{NS}$; Vacor diabetic group: with microvascular disease $(n=10), 2,299 \pm 201$ vs. without microvascular disease $(n=8)$, $2,346 \pm 236 \mathrm{NS})$.

\section{Discussion}

A number of different experiments in animals have suggested that the microvascular disease associated with diabetes is due to hyperglycemia or other factors associated with poor metabolic control. For example, experiments in rodents have shown that diabetes secondary to streptozotocin injection, alloxan administration, or pancreatectomy results in structural changes in the

Table II. IDD Group

\begin{tabular}{|c|c|c|c|c|c|c|c|c|}
\hline Patient code & Age & $\operatorname{Sex}(M / F)$ & $\begin{array}{l}\text { Duration of } \\
\text { diabetes }\end{array}$ & $\mathbf{H b A}_{\mathbf{1}}$ & Creatinine & $\begin{array}{l}\text { Retinopathy } \\
(+/-)\end{array}$ & $\begin{array}{l}\text { Proteinuria } \\
(+/-)\end{array}$ & $\begin{array}{l}\text { MCBM width } \\
\text { (mean } \AA \text { ) }\end{array}$ \\
\hline & $y r$ & & $y r$ & $\%$ & $m g / d l$ & & & \\
\hline 3 & 24 & $\mathrm{~F}$ & 4 & 14.0 & 0.8 & - & - & 2,568 \\
\hline 4 & 26 & $\mathrm{~F}$ & 5 & 11.9 & 0.9 & - & - & 2,839 \\
\hline 32 & 24 & $\mathbf{F}$ & 5 & 9.5 & 0.8 & + & - & 2,104 \\
\hline 33 & 24 & $\mathrm{~F}$ & 5 & 12.1 & 0.9 & + & - & 2,196 \\
\hline 34 & 27 & $\mathrm{~F}$ & 7 & 9.5 & 0.9 & + & - & 2,001 \\
\hline 35 & 25 & $\mathrm{~F}$ & 4 & 12.7 & 0.7 & - & - & 2,477 \\
\hline 36 & 18 & $\mathbf{M}$ & 3 & 12.1 & 1.0 & - & - & 1,833 \\
\hline 37 & 23 & $\mathbf{F}$ & 4 & 8.3 & 0.7 & - & - & 2,225 \\
\hline 41 & 26 & $\mathrm{~F}$ & 1 & 13.0 & 0.8 & - & - & 2,345 \\
\hline 42 & 29 & $\mathbf{M}$ & 2 & 13.1 & 0.8 & - & - & 2,460 \\
\hline 43 & 23 & $\mathbf{F}$ & 1 & 12.1 & 0.6 & - & - & 2,201 \\
\hline 55 & 27 & $\mathbf{M}$ & 1 & 14.2 & 1.1 & - & - & 1,563 \\
\hline 56 & 23 & $\mathbf{F}$ & 2 & 15.3 & 0.9 & - & + & 2,872 \\
\hline 67 & 33 & $\mathbf{F}$ & 5 & 10.0 & & - & - & 1,771 \\
\hline 68 & 53 & $\mathbf{F}$ & 26 & 8.6 & & - & - & 3,677 \\
\hline \multirow[t]{2}{*}{71} & 26 & $\mathbf{F}$ & $1 / 6$ & 14.4 & 0.6 & + & - & 1,276 \\
\hline & & & & & & & $1 / 16$ & \\
\hline Mean \pm SEM & $26.9 \pm 1.9$ & $3 \mathrm{M} / 13 \mathrm{~F}$ & $4.7 \pm 1.5$ & $11.93 \pm 0.54$ & $0.82 \pm 0.04$ & $4 / 16(25 \%)$ & $(6 \%)$ & $2,287 \pm 144$ \\
\hline
\end{tabular}

MCBM, muscle capillary basement membrane. 


\begin{tabular}{|c|c|c|c|c|c|c|c|c|}
\hline Patient code & Age & $\operatorname{Sex}(M / F)$ & $\begin{array}{l}\text { Duration of } \\
\text { diabetes }\end{array}$ & $\mathrm{HbA}_{\mathbf{t}}$ & Creatinine & $\begin{array}{l}\text { Retinopathy } \\
(+/-)\end{array}$ & $\begin{array}{l}\text { Proteinuria } \\
(+/-)\end{array}$ & $\begin{array}{l}\text { MCBM width } \\
\text { (mean A) }\end{array}$ \\
\hline & $y r$ & & $y r$ & \% & $m g / d l$ & & & \\
\hline 2 & 28 & $\mathbf{M}$ & 6 & 12.6 & 1.6 & + & + & 2,261 \\
\hline 5 & 37 & $\mathbf{F}$ & 5 & 11.0 & 0.9 & - & - & 3,083 \\
\hline 6 & 24 & $F$ & 5 & 12.3 & 0.8 & - & - & 2,742 \\
\hline 8 & 27 & $\mathbf{F}$ & 6 & 12.8 & 1.0 & - & - & 2,634 \\
\hline 9 & 54 & $\mathbf{F}$ & 5 & 10.8 & 0.7 & - & - & 1,575 \\
\hline 10 & 24 & $\mathrm{~F}$ & 5 & 12.7 & 0.8 & + & - & 2,104 \\
\hline 11 & 27 & $\mathbf{F}$ & 7 & 10.7 & 0.8 & - & - & 1,556 \\
\hline 12 & 28 & $\mathbf{F}$ & 5 & 12.8 & 0.7 & - & - & 1,625 \\
\hline 13 & 18 & $\mathbf{M}$ & 5 & 12.7 & 0.8 & + & - & 1,613 \\
\hline 38 & 22 & $F$ & 7 & 12.1 & 0.7 & - & - & 2,445 \\
\hline 39 & 26 & $F$ & 8 & 11.3 & 0.7 & - & - & 3,105 \\
\hline 40 & 24 & $\mathbf{F}$ & 7 & 12.9 & 0.7 & + & - & 3,755 \\
\hline 74 & 24 & $F$ & 5 & 11.5 & 0.7 & - & + & 3,046 \\
\hline Mean \pm SEM & $28.2 \pm 1.9$ & $3 \mathrm{M} / 15 \mathrm{~F}$ & $6.2 \pm 0.3$ & $12.08 \pm 0.17$ & $0.87 \pm 0.06$ & $8 / 18(44 \%)$ & $5 / 18(28 \%)$ & $2,320 \pm 148.7$ \\
\hline
\end{tabular}

MCBM, muscle capillary basement membrane.

kidneys that are very similar but not identical to those observed in humans with diabetic nephrectomy (27). Moreover, the prevention of the hyperglycemia in the diabetic rodents by either insulin administration or pancreatic transplantation prevented the development of these structural changes in the kidney (27). Similarly, in alloxan-induced diabetes in dogs, Engerman et al. observed that the poorly controlled hyperglycemic animals had an increased number of retinal microaneurysms in comparison with animals whose diabetes was well controlled (28). Additionally, thickening of the glomerular capillary wall and the mesangial region occurs more commonly and was more severe in the poorly controlled diabetic dogs (28). Streptozotocin-induced diabetes in monkeys has also been shown to result in both increased muscle and glomerular capillary basement membrane thickening (29). These studies and others, therefore, support the hypothesis that an elevated blood glucose level or other abnormalities that occur in association with poorly controlled diabetes lead to the microvascular changes that occur in patients with diabetes mellitus. It should be recognized, though, that to date, studies in humans have not demonstrated that tight metabolic control prevents or retards the development of microvascular disease (30-36).

Secondary diabetes has, in some reports but not all, been associated with increased thickening of the muscle capillary basement membrane, diabetic retinopathy, or diabetic nephropathy $(1,15-20)$. However, only a minority of patients with these conditions (chronic pancreatitis, hemochromatosis) develop overt diabetes, which raises the possibility that those individuals who become hyperglycemic may have been selected by a genetic predisposition to the development of diabetes. In the present study the potential confounding influence of a genetic predisposition contributing to the microvascular disease has been avoided. In the extensive Korean experience with Vacor poisoning, the ingestion of this agent has resulted in hyperglycemia in a very large percentage of individuals (26). As a result, Vacorinduced diabetes is the first model in humans analogous to the induced diabetic models in animals. This condition therefore presents a unique opportunity in which to study the relationship between hyperglycemia, independent of genetic diabetes, and microangiopathy in humans.

Table IV. Clinical Characteristics of Patients

\begin{tabular}{|c|c|c|c|c|c|c|c|c|}
\hline & Age & Sex & $\begin{array}{l}\text { Family history } \\
\text { of diabetes }\end{array}$ & $\begin{array}{l}\text { Duration of } \\
\text { diabetes }\end{array}$ & $\mathbf{H b A}_{\mathbf{I}}$ & Creatinine & Retinopathy & Proteinuria \\
\hline & $y r$ & & & $y r$ & $\%$ & $m g / d l$ & & \\
\hline $\operatorname{IDDM}(n=16)$ & $26.9 \pm 1.9$ & $3 \mathrm{M} / 13 \mathrm{~F}$ & $0 / 16$ & $4.7 \pm 1.5$ & $11.93 \pm 0.54$ & $0.82 \pm 0.04$ & $4 / 16(25 \%)$ & $1 / 16(6 \%)$ \\
\hline $\begin{array}{l}\text { Vacor diabetes } \\
\qquad(n=18)\end{array}$ & $28.2 \pm 1.9$ & $3 \mathrm{M} / 15 \mathrm{~F}$ & $0 / 18$ & $6.2 \pm 0.3$ & $12.08 \pm 0.17$ & $0.87 \pm 0.06$ & $8 / 18(44 \%)$ & $5 / 18(28 \%)$ \\
\hline
\end{tabular}


Table V. Summary of Basement Membrane Findings

\begin{tabular}{lll}
\hline & $\begin{array}{l}\text { MCBM width } \\
\text { (mean } \AA \text { ) }\end{array}$ & $\begin{array}{l}\text { Patients with MCBM } \\
\text { width 2 SD }>\text { mean } \\
\text { of control }\end{array}$ \\
\hline & & $\%$ \\
Control $(n=20)$ & $1,781 \pm 46.4$ & 5 \\
IDDM $(n=16)$ & $2,287 \pm 144.0$ & 63 \\
Vacor diabetes & $2,320 \pm 148.7$ & 56 \\
$\quad(n=18)$ & & \\
1 vs. 2 & $P<0.001$ & $P<0.001$ \\
1 vs. 3 & $P<0.001$ & $P<0.001$ \\
2 vs. 3 & NS & NS \\
\hline
\end{tabular}

MCBM, muscle capillary basement membrane.

The present study demonstrates that in humans without a family history of diabetes mellitus, Vacor-induced hyperglycemia leads to an increase in muscle capillary basement membrane width (Vacor-induced diabetics, 2,320 \pm 149 vs. controls, $1,781 \pm 46 \AA, P<0.001)$. The increase in muscle capillary basement membrane width observed in our patients with Vacorinduced diabetes was similar in degree to that observed in a group of age-, sex-, and duration-matched IDD (Vacor-induced diabetics, $2,320 \pm 149$ vs. IDD, $2,287 \pm 144 \AA$ ). $56 \%$ of the individuals with Vacor-induced diabetes and $63 \%$ of patients with IDD had a muscle capillary basement membrane thickness two standard deviations greater than the mean observed in controls.

Our laboratory has also had the opportunity to measure muscle capillary basement membrane widths in a few individuals in the United States who had Vacor-induced diabetes. In a patient reported by Miller et al. (21) we found a muscle capillary basement membrane thickness of $1,918 \pm 185 \AA$, and in two other patients $(23,24)$ the muscle capillary basement membrane width was $1,612 \pm 87 \AA$ and $2,261 \pm 185 \AA$, respectively. All three of these values are higher than those observed in concurrently measured nondiabetic individuals and are thus consistent with the observations of the present study. Lee et al. in a smaller group of Korean Vacor-induced diabetics has also observed a thickening of the muscle capillary basement membrane (37).

In addition to the thickening of the muscle capillary basement membrane, it should also be noted that in our patients with Vacor-induced diabetes of relatively short duration $(6.2 \pm 0.3 \mathrm{yr})$, $44 \%$ had evidence of retinopathy on routine funduscopic examination and $28 \%$ had proteinuria on routine urinalysis. These findings indicate that, as observed in animal experiments, the induction of diabetes by ingestion of a compound toxic to the beta cells of the pancreas not only results in hyperglycemia, but also leads to the microvascular changes associated with diabetes mellitus. Of course it is possible that Vacor ingestion per se leads to the microvascular changes observed, but this seems an extremely remote possibility.

The results of this study - along with $(a)$ the data presented in the Introduction section demonstrating that improved glycemic control results in a decrease in muscle capillary basement membrane width; $(b)$ the studies demonstrating that kidneys from nondiabetics transplanted into diabetic patients develop morphological changes similar to those that occur in diabetic nephropathy and that these changes can be prevented by tight metabolic control $(38,39)$; and $(c)$ the isolated case report dem- onstrating that the transplantation of diabetic kidneys into nondiabetic hosts results in the almost complete resolution of the diabetic lesion over a 7-mo period of observation (40)-all strongly support the hypothesis that the diabetic environment can be a primary cause and major aggravating factor in the microvascular changes of diabetics.

In summary, while data from this and other laboratories clearly demonstrate that genetic factors in the absence of hyperglycemia can cause thickening of muscle capillary basement width, the findings of the present study provide strong evidence that hyperglycemia, or some other abnormality that occurs in insulinopenic states, can itself cause the microvascular changes that occur in patients with diabetes mellitus.

\section{Acknowledgments}

We wish to thank Raymond Clouse for carrying out the electron microscopy, Mary Ellin Plummer for quantifying the basement membrane widths, Maggie Joe for her excellent secretarial assistance, and Dr. Y. Kim for assistance in coordinating this study.

Dr. Feingold is a recipient of a V.A. Clinical Investigator Award. This work was supported by National Institutes of Health grant AM 27479 and by the Medical Research Service, Veterans Administration.

\section{References}

1. Siperstein, M. D., R. H. Unger, and L. L. Madison. 1968. Studies of muscle capillary basement membranes in normal subjects, diabetic, and prediabetic patients. J. Clin. Invest. 47:1973-1999.

2. Vracko, R. 1970. Skeletal muscle capillaries in diabetics: a quantitative analysis. Circulation. 41:271-283.

3. Kilo, C., N. Volger, and J. R. Williamson. 1972. Muscle capillary basement membrane changes related to aging and to diabetes mellitus. Diabetes. 21:881-905.

4. Pardo, V., E. Perez-Stable, D. B. Alzamora, and W. W. Cleveland. 1972. Incidence and significance of muscle capillary basal lamina thickness in juvenile diabetes. Am. J. Pathol. 68:67-77.

5. Raskin, P., A. O. Pietri, R. Unger, and W. A. Shannon, Jr. 1983. The effect of diabetic control on the width of skeletal-muscle capillary basement membrane in patients with type I diabetes mellitus. $N$. Engl. J. Med. 309:1546-1550.

6. Camerini-Davalos, R. A., C. Velasco, M. Glasser, and J. M. B. Bloodworth, Jr. 1983. Drug-induced reversal of early diabetic microangiopathy. N. Engl. J. Med. 309:1551-1556.

7. Peterson, C. M., R. L. Jones, J. A. Esterly, G. E. Wantz, and R. L. Jackson. 1980. Changes in basement membrane thickening and pulse volume concomitant with improved glucose control and exercise in patients with insulin-dependent diabetes mellitus. Diabetes Care. 3: $586-589$.

8. Sosenko, J. M., O. S. Miettinen, J. R. Williamson, and K. H. Gabbay. 1984. Muscle capillary basement membrane thickness and long term glycemia in type I diabetes mellitus. N. Engl. J. Med. 311:694698.

9. Williamson, J. R., and C. Kilo. 1977. Current status of capillary basement membrane disease in diabetes mellitus. Diabetes. 26:65-73.

10. Camerini-Davalos, R. A., W. Oppermann, H. Rebagliati, 1979. Muscle capillary basement membrane width in genetic prediabetes. $J$. Clin. Endocrinol. Metab. 48:251-259.

11. Ganda, O. P., J. R. Williamson, J. S. Soeldner, R. E. Gleason, C. Kilo, A. Kaldany, J. P. Miller, M. R. Garovoy, and C. B. Carpenter. 1983. Muscle capillary basement membrane width and its relationship to diabetes mellitus in monozygotic twins. Diabetes. 32:549-556.

12. Barnett, A. H., A. J. Spiliopoulos, D. A. Pyke, W. A. Stubbs, E. Rowold, P. Hoffman, A. Faller, C. Kilo, J. P. Miller, and J. R. Williamson. 1983. Muscle capillary basement membrane in identical twins discordant for insulin dependent diabetes. Diabetes. 32:557-570. 
13. Steffes, M. W., D. E. R. Sutherland, F. C. Goetz, S. S. Rich, and S. M. Mauer. 1985. Studies of kidney and muscle biopsy specimens from identical twins discordant for type I diabetes mellitus. N. Engl. J. Med. 312:1282-1287.

14. Marks, J. F., P. Raskin, and P. Stastny. 1981. Increase in capillary basement membrane width in parents of children with Type I diabetes mellitus. Diabetes. 30:475-480.

15. Lonergan, P., and S. L. Robbins. 1959. Absence of intercapillary glomerulosclerosis in the diabetic patient with hemochromatosis. $N$. Engl. J. Med. 260:367-370.

16. Becker, D., and M. Miller. 1960. Presence of diabetic glomerulosclerosis in patients with hemochromatosis. N. Engl. J. Med. 263:367373.

17. Ireland, J. T., B. K. Patnaik, and L. J. P. Duncan. 1967. Glomerular ultrastructure in secondary diabetics and normal subjects. $\mathrm{Di}$ abetes. 16:628-635.

18. Ennis, G., M. Miller, F. M. Unger, and L. Unger. 1969. Intercapillary glomerulosclerosis in diabetics secondary to chronic relapsing pancreatitis. Diabetes. 18:333. (Abstr.)

19. Griffiths, J. D., I. W. Dymock, E. W. G. Davies, D. W. Hill, and K. Williams. 1971. Occurrence and prevalence of diabetic retinopathy in hemochromatosis. Diabetes. 20:766-770.

20. Verdonk, C. A., P. J. Palumbo, H. Gharib, and L. G. Bartolomew. 1975. Diabetic microangiopathy in patients with pancreatic diabetes mellitus. Diabetologia. 11:395-400.

21. Miller, L. V., J. D. Stokes, and C. Silpipat. 1978. Diabetes mellitus and autonomic dysfunction after vacor rodenticide ingestion. Diabetes Care. 1:73-76.

22. Pont, A., J. M. Rubino, D. Bishop, and R. Peal. 1979. Diabetes mellitus and neuropathy following vacor ingestion in man. Arch. Intern. Med. 139:185-187.

23. Prosser, P. R., and J. H. Karam. 1978. Diabetes mellitus following rodenticide ingestion in man. J. Am. Med. Assoc. (JAMA). 239:11481150.

24. Karam, J. H., P. A. LeWitt, C. W. Young, R. E. Nowlain, B. J. Frankel, H. Fujiya, Z. R. Freedman, and G. M. Grodsky. 1980. Insulinopenic diabetes after rodenticide (vacor) ingestion: a unique model of acquired diabetes in man. Diabetes. 29:971-978.

25. LeWitt, P. A. 1980. The neurotoxicity of the rat poison vacor. N. Engl. J. Med. 302:73-77.

26. Lee, T. H., M. W. Lee, K. Doi, and S. Baba. 1983. Vacor induced diabetes mellitus. In Diabetes Mellitus as Related to Over and Under Nutrition. S. Baba, S. Iwai, and U. Sukatow, editors. International Center for Medical Research, Kobe University School of Medicine. 131-139.

27. Mauer, S. M., M. W. Steffes, A. F. Michael, and D. M. Brown. 1976. Studies of diabetic nephropathy in animals and man. Diabetes. 25(Suppl. 2):850-857.
28. Engerman, R., J. M. B. Bloodworth, Jr., and S. Nelson. 1977. Relationship of microvascular disease in diabetes to metabolic control. Diabetes. 26:760-769.

29. Yasuda, H., Y. Harano, K. Kosugi, T. Nakano, M. Suzuki, Y. Tsuruoka, Y. Taniguchi, T. Nishimori, R. Kikkawa, and Y. Shigeta. 1984. Development of early lesions of microangiopathy in chronically diabetic monkeys. Diabetes. 33:415-420.

30. Job, D., E. Eschwege, C. Guyot-Argenton, J. P. Aubry, and G. Tchobroutsky. 1976. Effect of multiple daily insulin injections on the course of diabetic retinopathy. Diabetes. 25:463-469.

31. Eschwege, E., D. Job, C. Guyot-Argenton, J. P. Aubry, and G. Tchobroutsky. 1979. Delayed progression of diabetic retinopathy by divided insulin administration. A further follow-up. Diabetologia. 16:1315.

32. Lauritzen, T., K. Frost-Larsen, H. W. Larsen, and the Steno Study Group. 1983. Effect of one year of near-normal blood glucose levels on retinopathy in insulin dependent diabetics. Lancet. i:200-204.

33. Lauritzen, T., K. Frost-Larsen, H. W. Larsen, T. Deckert, N. Keiding, G. Nielsen, and The Steno Study Group. 1983. Continuous subcutaneous insulin (letter). Lancet. i:1445.

34. Holman, R. R., T. L. Dornan, V. Mayon-White, C. Orde-Peckar, J. Steemson, B. Smith, K. McPherson, C. Rizza, A. H. Knight, J. HowardWilliams, L. Jenkins, R. Rolfe, D. Barbour, P. Y. W. Poon, J. I. Mann, A. J. Bron, and R. C. Turner. 1983. Prevention of deterioration of renal and sensory-nerve function by more intensive management of insulin dependent diabetic patients. Lancet. i:204-208.

35. Kroc collaborative study group. 1984. Blood glucose control and the evolution of diabetic retinopathy and albuminuria. N. Engl. J. Med. 311:365-372.

36. University Group Diabetes Program. 1982. Effects of hypoglycemic agents on vascular complications in patients with adult onset diabetes: VIII evaluation of insulin therapy. Final Report. Diabetes. 31(Suppl. 5):1-81.

37. Lee, T. H., K. C. Choi, K. Park, and J. K. Choi. 1982. Thickening of capillary basal lamina of quadriceps muscle in vacor induced diabetic patients. Excerpta Med. Int. Congr. Ser. 223.

38. Mauer, S. M., J. Barbosa, R. L. Vernier, C. M. Kjellstrand, T. J. Buselmeier, R. L. Simmons, J. S. Najarian, and F. C. Goetz. 1976. Development of diabetic vascular lesions in normal kidneys transplanted into patients with diabetes mellitus. N. Engl. J. Med. 295:916-920.

39. Bohman, S. O., G. Tyden, H. Wilczck, G. Lundgren, G. Jaremko, R. Gunnarsson, J. Ostman, and C. G. Groth. 1985. Prevention of kidney graft diabetic nephropathy by pancreas transplantation in man. Diabetes. 34:306-308.

40. Abouna, G. M. 1983. Reversal of diabetic nephropathy in human cadaveric kidneys after transplantation into non-diabetic recipients. Lancet. 1:1274. 